The University of San Francisco

USF Scholarship: a digital repository @ Gleeson Library |

Geschke Center

Kinesiology (Formerly Exercise and Sport Science)

College of Arts and Sciences

2000

\title{
Does Bat Day Make Cents? The Effect of Promotions on the Demand for Major League Baseball
}

Mark McDonald

Daniel A. Rascher

University of San Francisco, RASCHER@USFCA.EDU

Follow this and additional works at: http://repository.usfca.edu/ess

Part of the Sports Management Commons

\section{Recommended Citation}

McDonald, Mark and Rascher, Daniel A., "Does Bat Day Make Cents? The Effect of Promotions on the Demand for Major League Baseball" (2000). Kinesiology (Formerly Exercise and Sport Science). Paper 1.

http://repository.usfca.edu/ess/1

This Article is brought to you for free and open access by the College of Arts and Sciences at USF Scholarship: a digital repository @ Gleeson Library | Geschke Center. It has been accepted for inclusion in Kinesiology (Formerly Exercise and Sport Science) by an authorized administrator of USF Scholarship: a digital repository@ Gleeson Library | Geschke Center. For more information, please contact repository@usfca.edu. 


\title{
Does Bat Day Make Cents? The Effect of Promotions on the Demand for Major League Baseball
}

\author{
Mark McDonald \\ University of Massachusetts at Amherst
}

\author{
Daniel Rascher \\ University of San Francisco \\ Navigant Consulting
}

\begin{abstract}
A primary objective of sport marketers in the professional sport setting is to develop strategies to increase game attendance. Historically, one of the strategies to accomplish this goal has been the utilization of special promotions. This paper studied the impact of promotions on attendance at professional sport games. Specifically, this research examines (a) the overall effect of promotions on attendance, and (b) the marginal impact on attendance of additional promotional days. Using a data set containing 1,500 observations, we find that a promotion increases single game attendance by about $14 \%$. Additionally, increasing the number of promotions has a negative effect on the marginal impact of each promotion. The loss from this watering down effect, however, is outweighed by the gain from having an extra promotion day.
\end{abstract}

A key objective of all professional sport marketers is to increase game attendance. The perishable nature of the spectator sport product places a premium on sales and marketing in this industry. Unsold seats not only result in reduced gate receipts, but also forfeit potential auxiliary revenue from parking, concessions, and merchandise sales. Furthermore, increasing competition from the more than 25 professional, minor league, and amateur sport sanctioning bodies, along with the broader entertainment industry, is pressuring professional sport teams to aggressively promote their product (Burton \& Cornilles, 1998).

As competition for the entertainment dollar continues to escalate, evaluating the relative impact of price and nonprice promotions on attendance gains in import. Attendance numbers from Major League Baseball (MLB) underscore this issue. Average MLB attendance in 1996, for example, was 26,889. This represents

Mark McDonald is with the Sport Management Program at the University of Massachusetts, Amherst, MA 01003. Daniel Rascher is with Navigant Consulting, Emeryville, CA 94608; and the Department of Sport Management at the University of San Francisco, San Francisco, CA 94117. 
only $53 \%$ of ballpark capacity (Take 'em Out, 1998). Furthermore, 24 of 28 MLB teams failed to fill their stadiums to $75 \%$ capacity annually. MLB teams have relied heavily on sales promotions as a method to increase attendance (Branvold \& Bowers, 1992).

Unfortunately, the effectiveness of this promotional strategy remains a perennial question. This paper seeks to provide some answers by examining (a) the overall effect of promotions on attendance, and (b) the marginal impact on attendance of additional promotional days. In terms of developing a promotional strategy, the results can be utilized to determine whether it is more successful to have many promotions or a few and to assess the relative effectiveness of various promotional options.

\section{Literature Review}

While this research focuses on the impact of promotions on attendance, it should be noted that numerous studies have examined a myriad of variables that influence attendance at sporting events. These studies have been within the professional and intercollegiate context, with a few recent examples involving the minor leagues. Some of the variables explored in these studies include the team's won-lost record (Becker \& Suls, 1983; Drever \& MacDonald, 1981; Noll, 1974), the probability of the home team winning (Rascher, 1999), star players (Noll, 1974; Schurr, Wittig, Ruble, \& Ellen, 1987; Schwartz, 1973; Scully, 1974), television broadcasts (Fizel \& Bennett, 1989; Zhang \& Smith, 1997); game schedules (Hill, Madura, \& Zuber, 1982), ticket prices (Bird, 1982; Siegfried \& Eisenberg, 1980), pre-event marketing (Jones, 1984; Zhang, Pease, Hui, \& Michaud, 1995), and the effect of weather (Noll, 1974).

For marketers, it is important to classify these variables as either controllable or uncontrollable. Many of these variables, such as weather conditions, existence of star players, and game schedules, are not under the direct supervision of sport team marketers. While understanding the impact of these variables helps explain variations in attendance patterns, marketers should focus their attention on variables that they can control. Promotions, for example, are completely under the control of professional sport franchises (Wall \& Myers, 1989).

Several studies have included promotions as one of many independent variables affecting attendance. Hill, Madura, and Zuber (1982) found the promotion variable positively and significantly related to attendance. Other studies have also concluded that promotions are attendance generators (Siegfried \& Eisenberg, 1980; Wall \& Myers, 1989). These researchers have invariably coded promotions as a binary variable equaling one if there was a special event or promotion at the stadium, and zero otherwise. While providing evidence as to the positive influence of promotions, issues related to the impact of frequency, promotional schedules, and effectiveness of various giveaway items were not examined.

While economists have traditionally treated promotions as a dummy $(0 / 1)$ variable, the importance of sales promotions to the promotional mix of professional sport franchises merits further elaboration. As with all industries, promotion comes in the forms of advertising, publicity, public relations, and sales promotions. 
Sales promotions, however, have been the prominent form of promotion for sport teams. According to Kotler (1994), sales promotion "consists of a diverse collection of incentive tools, mostly short term, designed to stimulate quicker and/or greater purchase of particular products/services by consumers or the trade" (p. 664).

In professional sport, sales promotions have traditionally been in the form of price or nonprice promotions (Mullin, Hardy, \& Sutton, 1993). Price promotions occur when everyone or a selected group is admitted to the game at less than the regular price. Some examples of price promotions include 2-for-1 night, seniors' night, or family night. Nonprice promotions are those games where everyone or a selected group of fans receive merchandise or when value-added entertainment (i.e., firework displays, San Diego Chicken Night) is provided. Giveaways range from classics such as bat days and helmet days, to the trendier Beanie Baby and CD-ROM giveaways (Take 'em Out, 1998).

There is a growing trend within professional sports toward sponsored promotions - corporations with sponsorship packages using promotional nights to distribute a product (Cornwell, 1995). By incorporating promotional night giveaway opportunities into sponsorship packages, sport organizations eliminate some of the up-front costs associated with these types of promotions. However, since the sponsors are saving the team money, they may expect more benefit from the rest of their sponsorship package or simply pay a cheaper price for the sponsorship rights. By not having to purchase items and allowing the sponsors to utilize inventoried product, the professional team reduces the overall costs associated with the attendance benefit garnered from the promotion.

There has been a dramatic increase in the use of promotions by professional sport teams. The number of special promotions held at home games by the San Francisco Giants, for example, rose from only $13 \%$ in 1980 to $28 \%$ in 1996 . With this increase, has there been an associated decrease in the marginal impact of promotion? Are fans "cherry picking" which games to attend?

In all industries, rapid growth in the use of sales promotions has resulted in promotional clutter, with a danger that consumers will become increasingly immune to their influence (Kotler, 1994). While this concept makes intuitive sense, there has been no empirical support for this concept in the sport marketing literature. There is, however, theoretical support (Helson, 1964) for the expectation that frequency of price promotions will have a negative impact on sales response to price promotions.

Adaptation-level theory (Helson, 1964) indicates that exposure to past stimuli (i.e., price) determines the "adaptation level" or the reference price. Thus, frequent price promotion results in the lowering of the perceived reference price. Future price promotions, when evaluated against this lower reference price, are judged less attractive by consumers. The existence and impact of reference prices on purchase behavior has been empirically tested (Kalwani, Yim, Rinne, \& Sugita, 1990; Kamen \& Tomen, 1970; Nagle, 1987; Winer, 1986). The direct effect of frequency of price discount promotions on short-term sales response has been tested within the context of retail grocery stores (Kumar \& Pereira, 1995). Results indicate that the effect of frequency of price promotion depends on the extent of consecutive 
scheduling, with the interaction of these two variables negatively affecting the short-term sales response. That study, however, involved products and not services, and focused entirely on price promotions.

\section{Method}

The cross sectional data contains 1,500 observations, one for each home game played by 19 Major League Baseball teams during the 1996 season. Each observation represents a particular game and contains the dependent variable, game attendance, which is used as a proxy for quantity sold. Additionally, over 50 independent variables are used as controls in explaining attendance variation across teams throughout the season.' Some of the values for these variables change from game to game (observation to observation), while others are constant for a particular team throughout the season but vary across teams ${ }^{2}$. In order to assess its true effect, it is necessary to be able to separate the effect of promotions from other factors of demand.

\section{The Dependent Variable}

Table 1 shows team-by-team simple statistics for the dependent variable, attendance. Attendance ranges from 6,021 fans (an April midweek Oakland A's game against a weak drawing Milwaukee club) to 57,467 fans (the opening day game for the Seattle Mariners) with a mean close to 27,000. Unlike the National Basketball Association where most games sell out, baseball games have a wide range of attendance figures allowing for the possibility of uncovering determinants of demand.

\section{Time Varying Independent Variables}

Included in each observation are variables that change from game to game for a particular team. Some of these relate to conditions of the game while others relate to team quality. The former will be described first, followed by the latter.

There are two variables that are of major interest for the empirical analysis of promotions - whether or not the home team was having a promotion that game and a measure of the cost of the promotional item. The average number of promotional dates for a team is 26 , translating into $32 \%$ of home games. The average marginal cost of each item is $\$ 2.19$, with a low of $\$ 0.40$ (a magnetic schedule) and a high of $\$ 4.95$ (a youth replica baseball jersey). ${ }^{3}$ Presumably, the value of an item affects the demand for attending the game. Cost is being used as a proxy for the value of the item.

Two measures of game excitement are the average number of runs scored in the previous 10 games for the home and visiting team, respectively. It is expected that the sign will be positive because pundits claim that today's fan enjoys a high scoring affair. However, it is possible for the sign to be negative if fans desire a pitching duel. This could be an interesting test of the pundits' claim.

To capture the effect of possible changes in player quality levels (from learning by doing or even trades) during the course of the season, the number of wins in the last 10 games for both the home and visiting teams is used and is expected to exert 


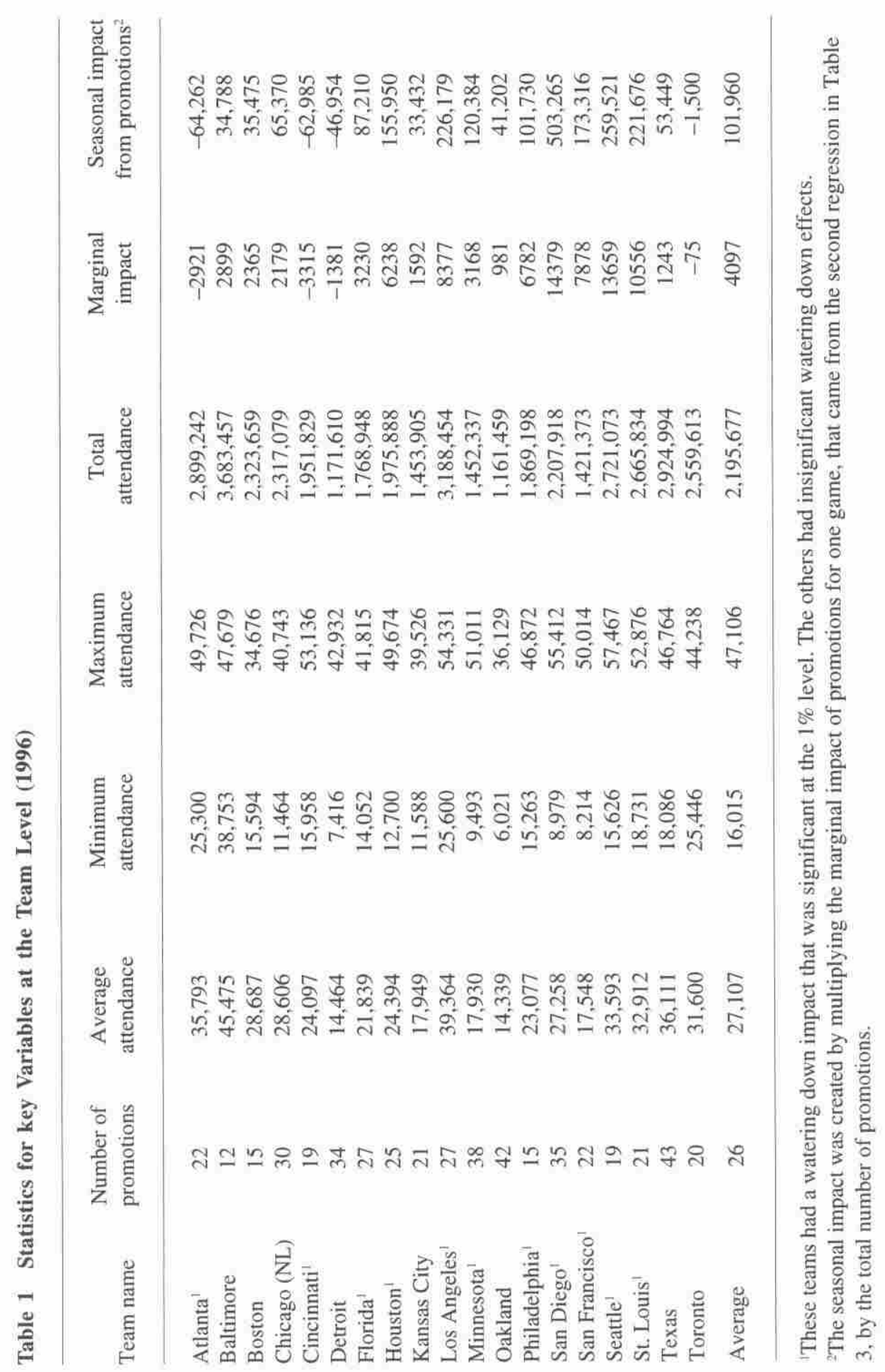


a positive influence on attendance. This variable is generally reported in the newspaper and, thus, is potentially seen by fans and incorporated into their decisionmaking process.

Another measure of team quality is whether a team is in contention for a division title. A proxy, the number of games behind the division leader, is used, but is interacted with the percentage of games left in the season. This distinguishes between being ten games out in May (still in contention) or ten games out in September (out of the race). The current percentage of games played (e.g., 30 of 162 games $=18.5 \%$ ) is used as a type of trend variable because many of the timevarying regressors (pitcher wins and losses) increase simply because the season wears on.

Unlike most other sports, the quality of a baseball team changes from game to game because a different starting pitcher is used each game (typically a rotation of 4 or 5 pitchers is used throughout the season). To capture this effect, the current wins, losses, and earned run average of both the home and visiting starting pitcher is used. It is expected that more wins, fewer losses, and a lower earned run average for both pitchers will increase attendance, but there should be a larger effect for the home team pitcher.

It is possible that fans relate more to the past career performances of a particular pitcher in making their purchasing decisions, especially at the beginning of a season. Career wins, losses, and earned run average for both the home and visiting starting pitchers is entered as a covariant and expected to have the same sign as the current season version of these variables.

The independent variables above are the team quality factors that vary from game to game. There are a number of interesting game condition variables unrelated to team quality. A weekend dummy variable is used to indicate whether a game is played on the weekend. A weekend game is expected to have a positive effect on attendance, because the opportunity cost of attending a game on the weekend is lower than during the week for people that have a standard workweek. Further, each team plays every Friday night, Saturday, and Sunday, but not each day during the week. Thus, the owners must feel that weekend games draw more fans than weekday games or else they wouldn't schedule so many of them. In fact, $48 \%$ of games are weekend games. An evening variable is also included for essentially the same reason. Additionally, an opening day variable is used to capture the wellknown positive effect that opening day has on attendance.

The temperature and degree of cloudiness at game time are probable factors in the decision to attend a baseball game. Warmer temperatures (although not too warm) and clearer skies are likely to induce higher fan turnouts. The cloudiness index ranges from 0 to 9 with 9 being very cloudy. The average cloudiness of the 1,500 games is about 2. The temperature ranges from 33 to 100 degrees Fahrenheit with a mean and median of about 72.5 .

One measure of the importance or excitement of a game is whether the two teams are rivals. Most rivalries are between two teams in the same division within the league. Additionally, divisions are usually geographically based. Thus, these official rivalries are also likely to be sociological rivalries, e.g., the San Francisco 
Giants and the Los Angeles Dodgers. A dummy variable was created to denote a game between rivals and is defined as teams within the same division.

Scully (1974), using baseball data from 1967, shows that Black pitchers were discriminated against at the gate with fewer fans showing up to watch them pitch. Indicator variables for Latino, Black, and Asian starting pitchers for both the home and away team are created to assess whether customer discrimination against certain races is a factor of demand. About $6 \%$ of the starting pitchers are Black, about $15 \%$ are Latino, and only two pitchers (Hideo Nomo and Chan Ho Park, both of the Los Angeles Dodgers) are Asian.

To measure the uncertainty in the outcome of the contest, the probability that the home team will win a particular game was created by converting the pregame odds data. On odds betting of this type, there is no vigorish or commission for the bookie. Instead, the odds for betting on the favorite are not symmetrical to the odds for betting on the underdog. For example, if the home team's line is 175 , and the visiting team's line is 165 , with the home team favored, a $\$ 175$ bet placed on the home team will pay $\$ 100$ if the home team wins and a $\$ 100$ bet placed on the visiting team will pay $\$ 165$ if the visiting team wins. The bookie makes a profit because the odds are not symmetric, and bettors place bets on both the underdog and the favorite.

To get a probability that the home team will win from the odds data, assume that the odds presented are for a fair bet. Then, if the probability that the home team will win is $\mathrm{P}_{h}, 100 \mathrm{P}_{\mathrm{h}}-175\left(1-\mathrm{P}_{\mathrm{h}}\right)=0$ implying that $\mathrm{P}_{\mathrm{h}}=0.636$. For a bet placed on the visiting team, the fair bet equation, $165 \mathrm{P}_{\mathrm{h}}-100\left(1-\mathrm{P}_{\mathrm{h}}\right)$, yields $\mathrm{P}_{\mathrm{h}}=0.623$. These probabilities are not the same because the difference allows the bookie to make a profit. The average of the two will be used here for the home team's probability of winning. In this case, $\mathrm{P}_{\mathrm{h}}=0.63$, or the home team has a $63 \%$ chance of winning the game. The resulting probabilities for the home team winning have an average of $54 \%$ with a minimum of $25 \%$ and a maximum of $82 \%$.

\section{Time Constant Independent Variables}

There are a number of potentially important independent variables that are constant throughout the season for a given team but vary across teams. One measure of the cost of attending a game is the Fan Cost Index from the Team Marketing Report. This index assumes a family of four purchases a fixed number of products (four hot dogs, four sodas, two peanuts, two caps, four mid-level tickets, and parking). The average Fan Cost Index is $\$ 103$ with a minimum of $\$ 81$ and a maximum of $\$ 122$.

The local unemployment rate and the local population are candidates for inclusion in a demand model. The expected effects are negative and positive, respectively. The racial composition of the local geographic area, if baseball appeals to certain cultures more than others, may affect attendance levels. Hoang and Rascher (1999) show that National Basketball Association annual attendance figures are partially predicted by the percentage of the local population that is Black. Here, the percentage Black and the percentage Latino are used to capture cultural 
differences across baseball cities. It will be interesting to see if and how the sports differ in this respect.

Owners believe that characteristics of the baseball park affect attendance since these are part of the product space. The data set contains two variables related to stadium age. One is an indicator variable that takes on one if a stadium is new (built since 1987, which is the new generation of stadia) and zero if it is old. Also, because of the allure of the two classic ballparks, Wrigley Field in Chicago and Fenway Park in Boston, a dummy variable is created for them.

A measure of alternative recreation (from the Places Rated Almanac) is included as a factor in determining annual attendance figures in order to capture the notion of substitute products for professional baseball. This measure includes items such as the number of golf courses, bowling alleys, beaches, lakes, or pools, all adjusted for population. Pundits consistently claim that West Coast fans are more fickle either because many more of them are transplants than fans in eastern cities, or because of the presumably extra recreation available in West Coast cities.

Finally, the number of home team and visiting team wins from the previous season is used as a measure of expected quality. This may be more important at the beginning of the season but is probably also a factor in season ticket sales, which in turn affect game-by-game attendance figures throughout the season. Table 2 shows simple statistics for the interpretable independent variables.

\section{Results}

There are two questions being analyzed to more fully understand the effects of promotions on attendance. First, do promotions work? Second, is there a watering down effect from fans being overexposed to promotions?

\section{Do Promotions Work?}

Baseball teams are in competition for consumers' entertainment dollars. To be successful, a team must offer a variety of peripheral products in case the game itself isn't of high quality. This helps smooth out the value of the overall experience from game to game. One of the product dimensions is to offer free giveaways to fans in order to entice them to come to a baseball game. Fans learn about which dates are promotional dates through radio, TV, PA, print, and team pocket schedules.

In order to assess whether this advertising works, we examined the determinants of demand for each game to see how they explain variations in attendance. Based on previous research and knowledge of demand factors, a unique group of control variables were included. This enabled us to interpret the attendance effect of having a promotion with confidence.

Because of the possibility of truncation of the dependent variable due to sellouts, a censored regression was run. It is similar to a tobit analysis except that it allows the dependent variable to have more than one truncation point, that is, a different one for each stadium capacity. The results were virtually identical to those from an OLS analysis. This is not surprising since there were only 29 sellouts out of a possible 1,500 games. 
Table 2 Simple Statistics of the Game-By-Game Baseball Data

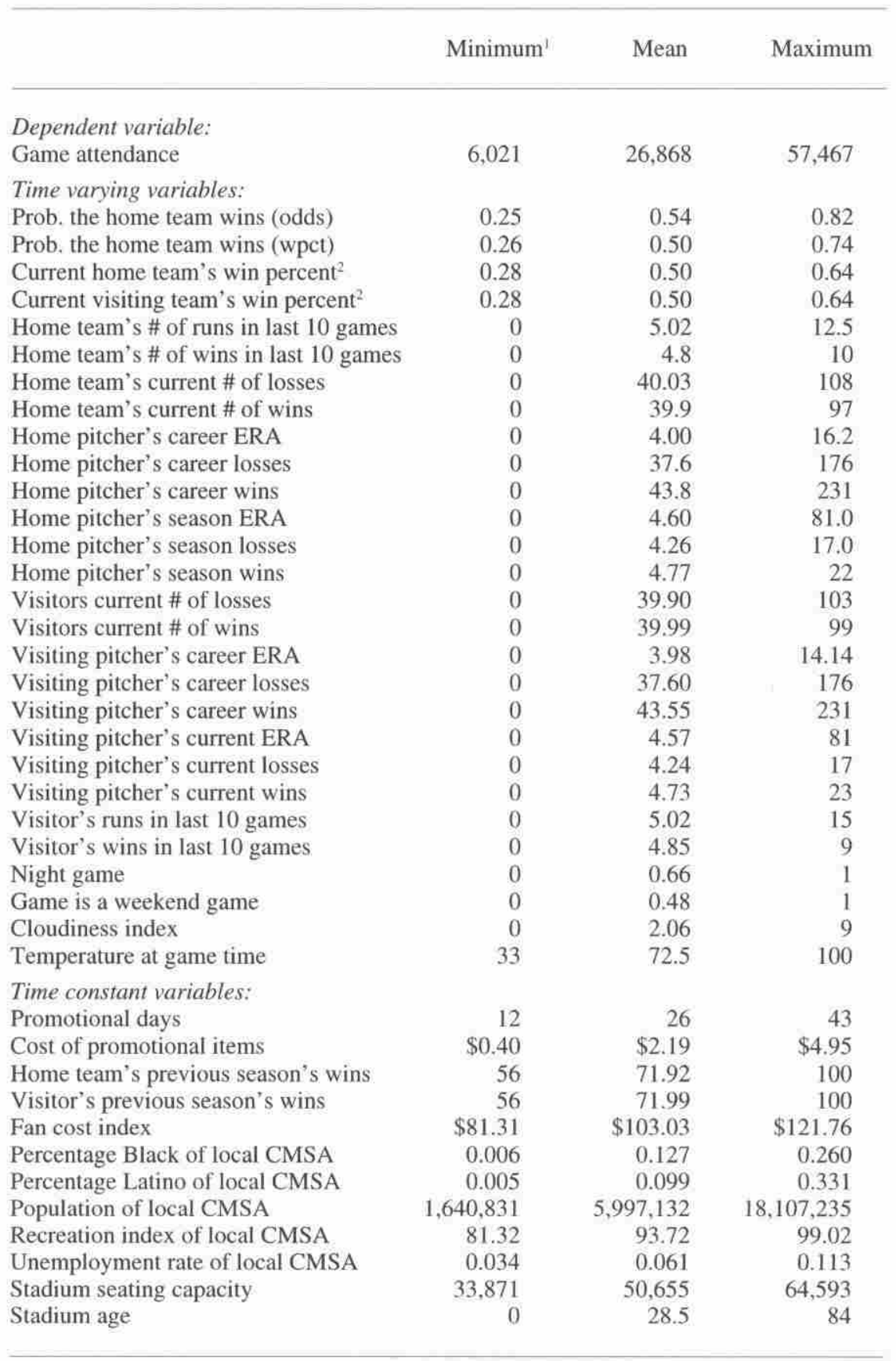

'Many of the observations are zero because of being measured for the first game of the season.

${ }^{2}$ These variables are for the 2 nd half of the season due to excess volatility at the beginning of the season. 
Another potential data problem is that the errors for an n-game series between two teams may not be independent. It is expected that across different groups of games (a three-game series for example), there exists independence of the errors but not necessarily within groups. This type of clustered correlation leads to understating the standard errors. A robust estimator of the variance was used to correct the standard errors.

Table 3 shows the results of the analysis. ${ }^{4}$ Overall, about two-thirds of the variation in game-by-game attendance is explained by the regression. Promotional games increased attendance by about 3,893 fans per game, all else equal. In other words, the average increase in attendance is about $14 \%$ from having a promotion. Thus, promotions do affect the short run demand for baseball games. ${ }^{5}$

\section{Is There a Watering Down Effect?}

The retail industry realizes that if they have too many discount sales throughout the year, consumers will get used to it and be less likely to react strongly to a particular sale. Some teams in baseball have a few promotions (Baltimore and Boston), while others have giveaways at over half of their home games (Texas and Oakland). What strategy is being employed in these cases and is it optimal? Will fans in Baltimore scrutinize their pocket schedules and make plans for the few key dates that have promotions, while Oakland A's fans realize that if they miss a particular game with a giveaway, there will be another one right around the corner, thus decreasing their incentive to attend a specific game?

Team-specific promotion date variables were created to answer this question. Eleven of the nineteen team-specific promotion variables were significant at the $1 \%$ level. ${ }^{6}$ If the promotional attendance impact decreases from increasing the number of promotions, then we should expect to find a negative correlation between the coefficient (marginal impact) on each of the team-specific promotional indicator variables and the number of promotions each team has, ceteris paribus. The correlation is -.21 , which is significant at the $5 \%$ level. Thus, a greater number of promotions results in a saturating effect on fans' demand for attending promotional games. The average impact is about $2 \%$ of total attendance or about $1 / 7$ of the baseline promotion impact found in the previous section ( $2 \%$ of $14 \%)$.

However, it still may be more profitable to have many, albeit less effective, promotions than a small number of highly effective promotions. One measure of success is the total net gain in attendance due to promotions. This is easily measured by multiplying the marginal impact by the number of promotions to get the seasonal marginal impact of giveaways on attendance. Even though Minnesota had about half of the per game promotional impact that Philadelphia had, their total seasonal impact was larger because they had more promotions.

Of the top 5 total seasonal impacts from promotions, three teams had more than the average number of promotion days, and two had below the average number of promotion dates. However, a correlation between the number of promotion days and the total seasonal impact from promotions was 0.42 , which is significant at the $1 \%$ level. Thus, it appears that more is better (i.e., regardless of the marginal impact per promotion date, it is strategically optimal to have many promotions rather than few promotions). ${ }^{8}$ 


\section{San Francisco Giants Analysis}

To further examine this issue, we gathered data over two seasons for the San Francisco Giants (1979 and 1996). Thus, both a cross-sectional data set (above) and a panel data set were used to corroborate the results. Because of the difficulty in obtaining control variables for the 1979 season, our total data set consists of four control variables in addition to the variable of interest, a promotional indicator variable. ${ }^{9}$ The results show that the marginal impact of a promotion during the 1979 season was $70 \%$ higher than during the 1996 season. This is not surprising since the 1996 season had 22 promotion days, and the 1979 season had 10 promotion days. Therefore, similar to our findings for the cross-sectional data set, there is a watering down effect on attendance impact from having a greater number of promotion days.

\section{Promotional Cost Analysis}

An alternative question faced by sport marketers is whether the quality of the promotion matters. While in all likelihood quality does matter, as with other consumer purchases, there may be incomplete information available to the consumer. Specifically, the consumer may not be able to observe the quality of the giveaway simply from its description in the pocket schedule or other advertising.

In order to answer this question, we examined the 145 games where we had the cost paid by the team for the promotional item. This served as our proxy for quality. As shown in Table 3, for each $\$ 1$ increase in the cost of the giveaway, about 2,688 additional fans were attracted. Not only do promotions impact attendance, but the quality of the promotion is also a significant factor.

\section{Conclusions and Future Research}

In summary, (a) promotions have a discernible 14\% impact on attendance, and (b) there is a slight watering down effect of too many promotions. The loss from this watering down effect, however, is outweighed by the gain from having an extra promotion day. Given the significant marginal impact of promotions on attendance, the increasing number of special promotions offered by professional sport franchises is not surprising.

The import of these types of promotions is further supported by the shifting rationale for running promotions. Promotions were once used exclusively as incentives to get more fans to come to games. Today, promotions are frequently part of the overall sponsorship package and are used to advertise the promotional sponsors' products to whomever attends the games. Thus, successful promotions now satisfy the two-prong objective of fulfilling corporate sponsor goals and increasing the number of patrons. With the growing need to grow revenue streams, promotions simultaneously increase monies from corporate sponsors and auxiliary income sources.

While this research sheds some positive light on the role of special promotions in the professional sport setting, it also raises a number of issues to be addressed by future research. One concern is that the baseline findings may be an 


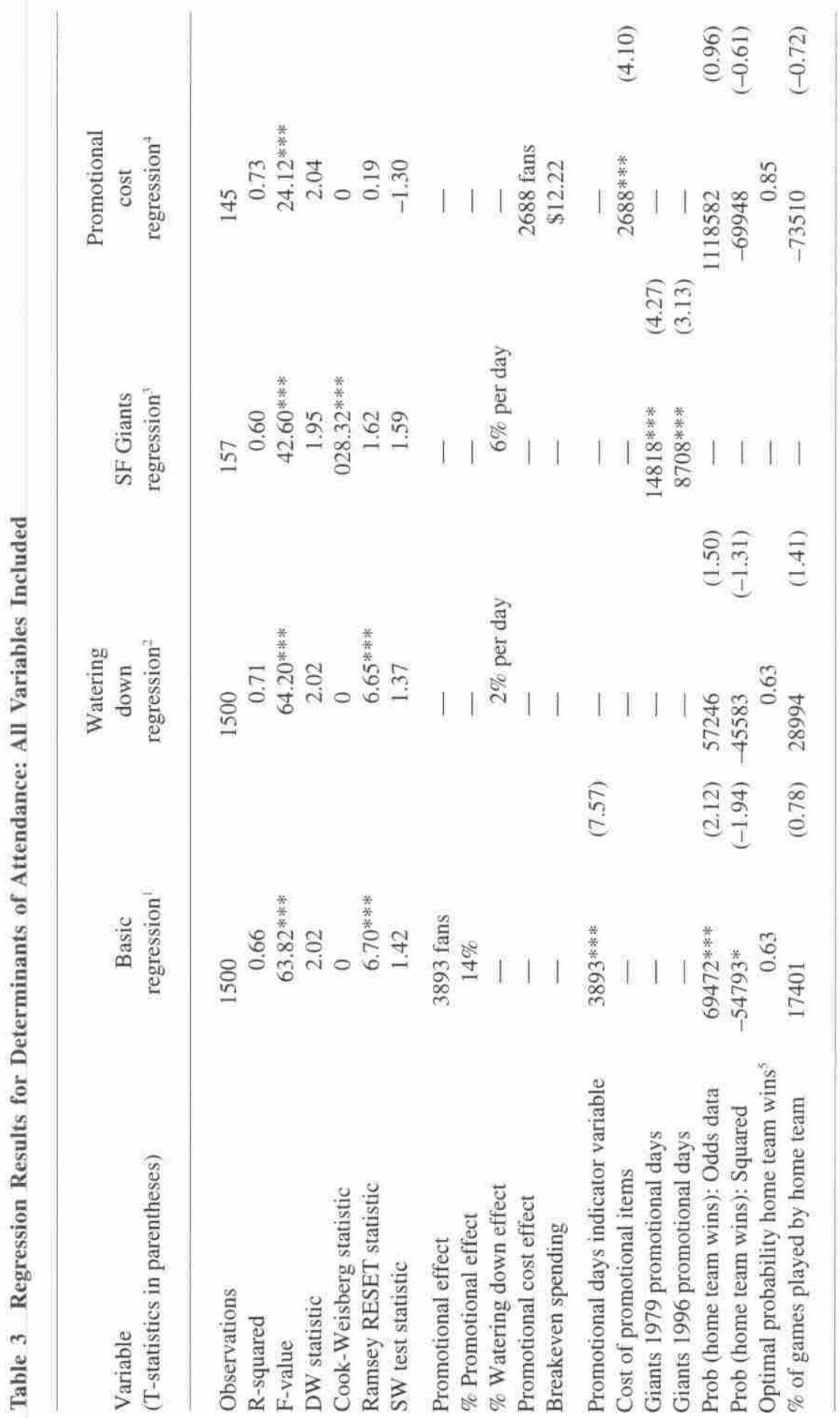




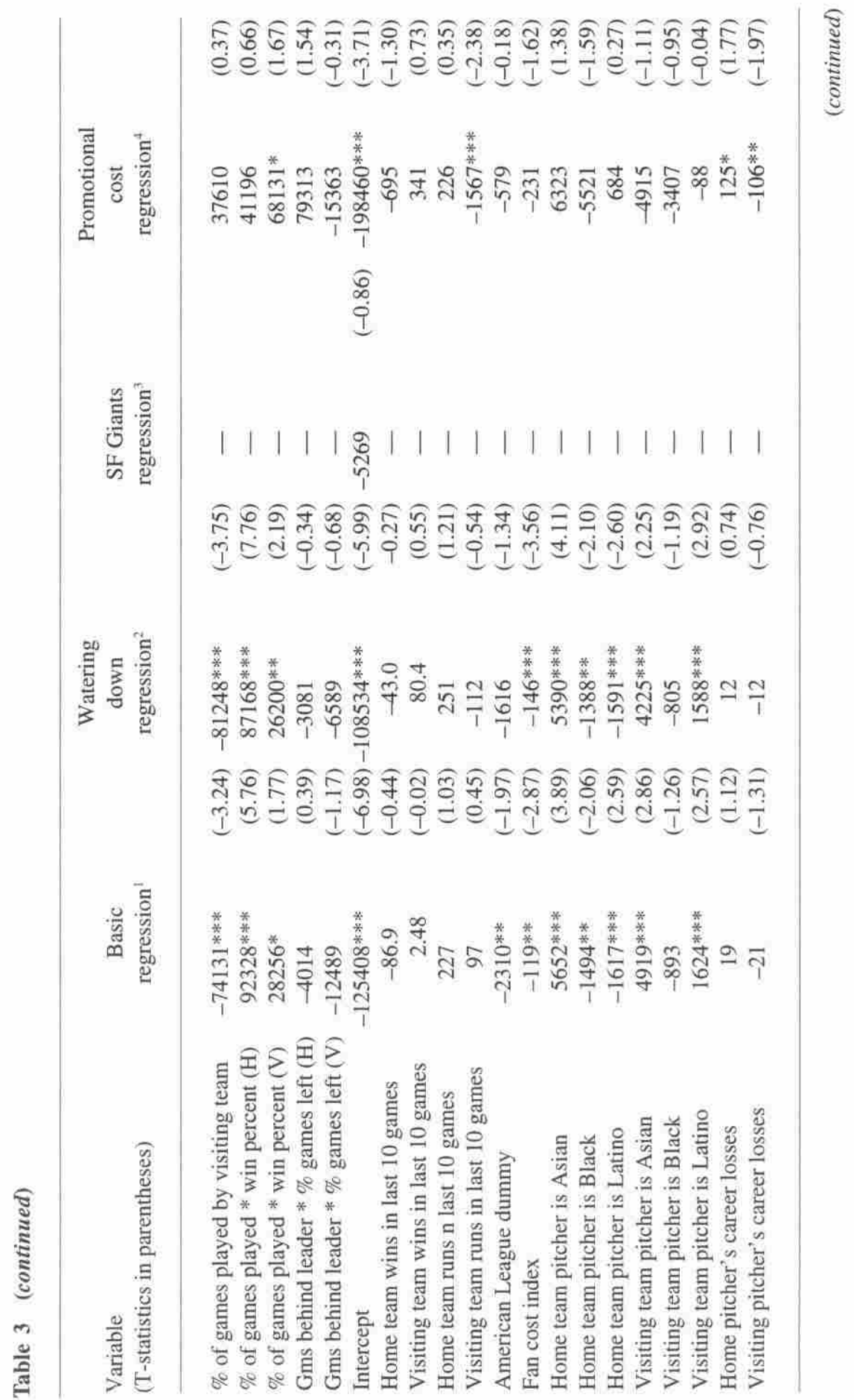




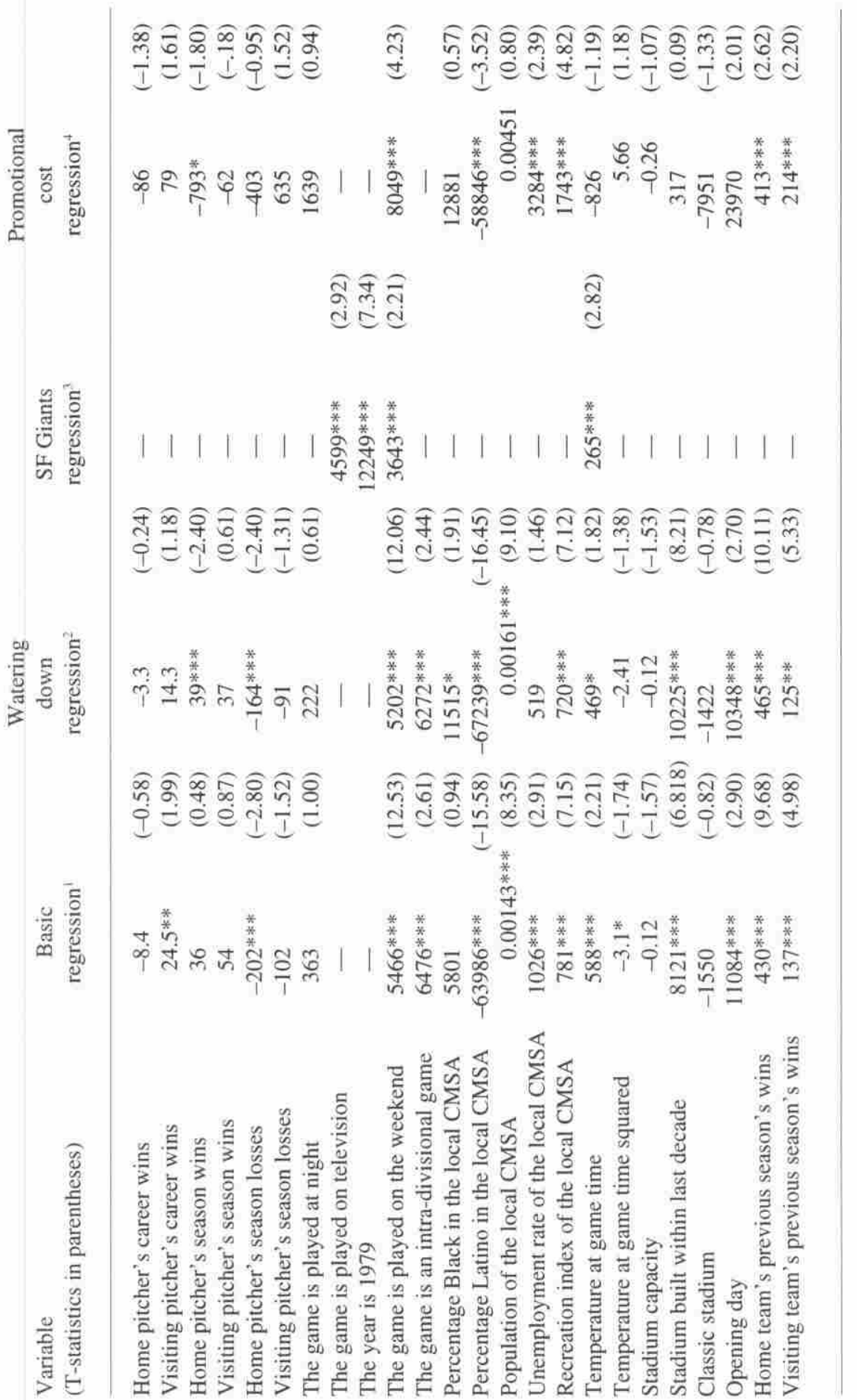




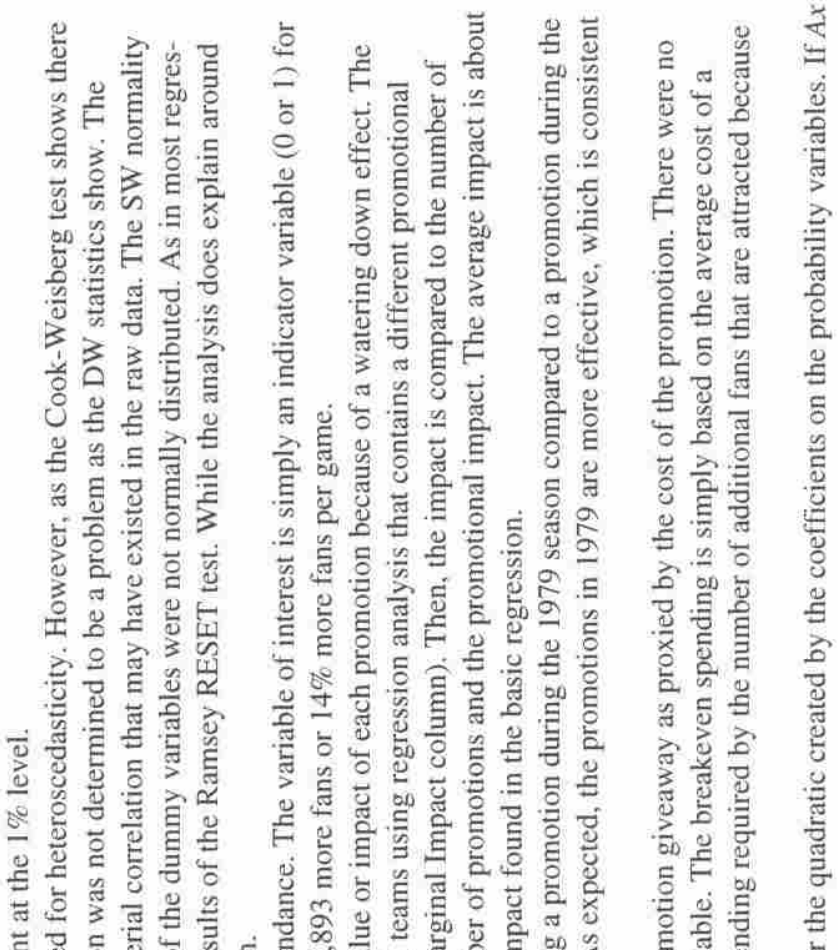

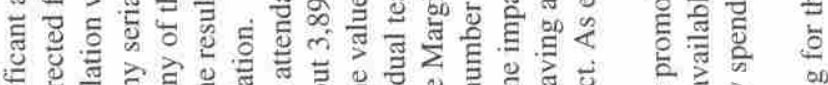

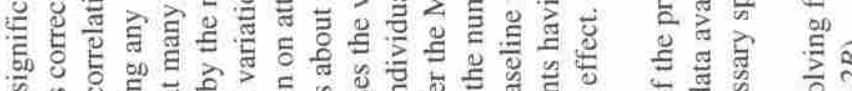

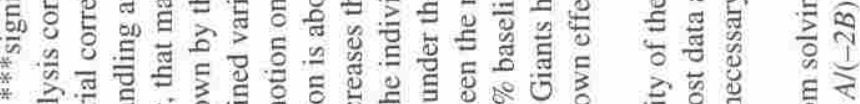

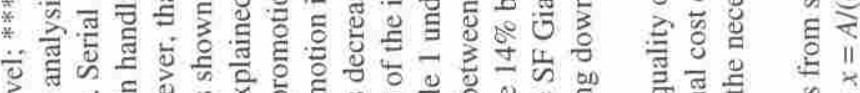

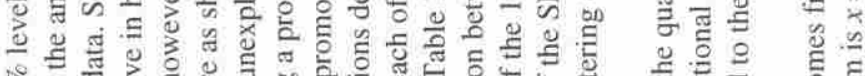

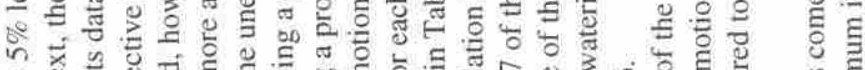

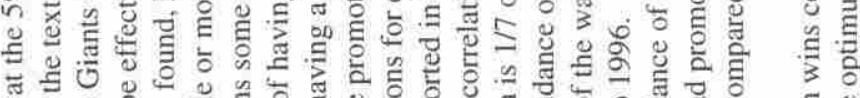

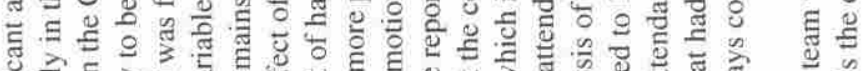

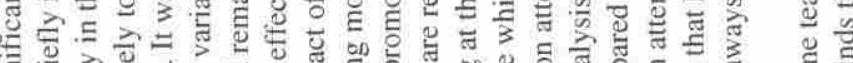

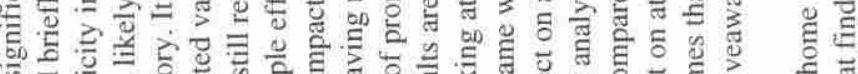

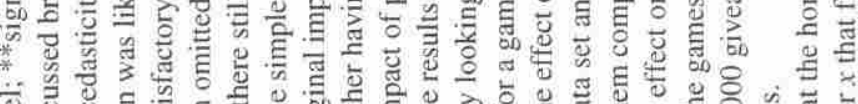

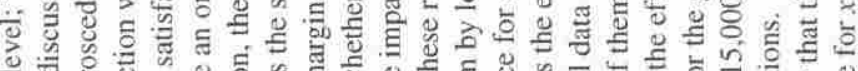

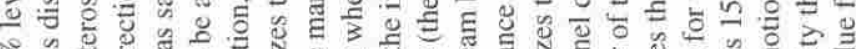

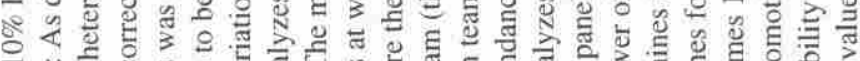

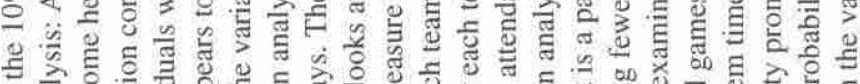

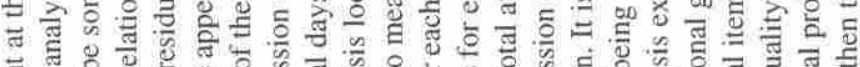
=

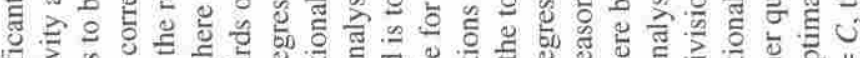

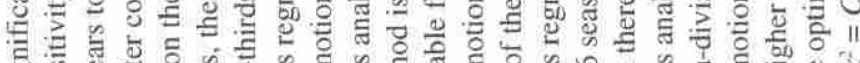

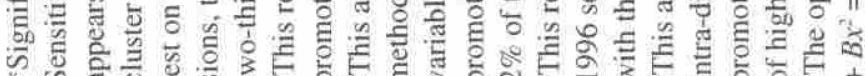




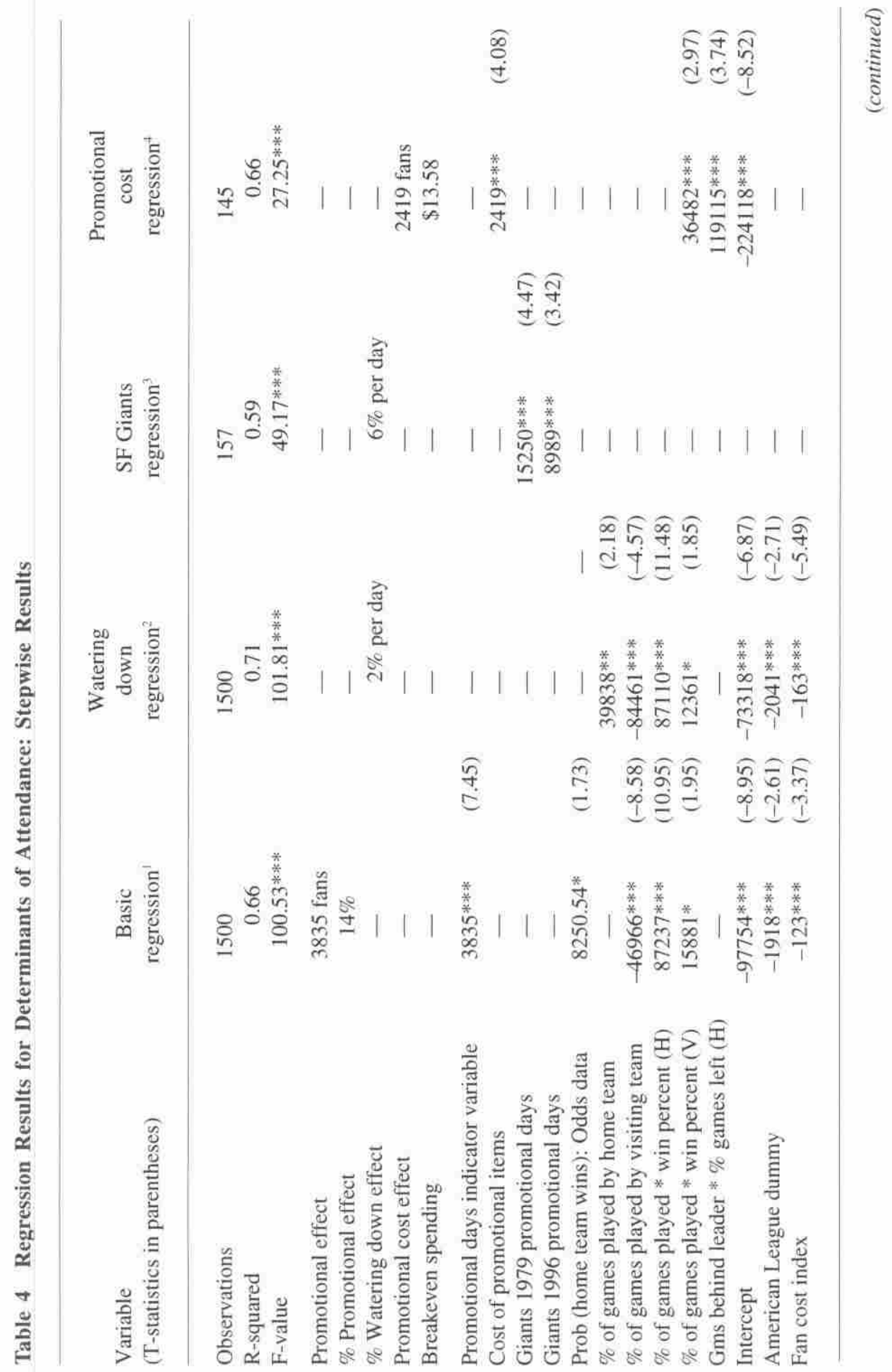




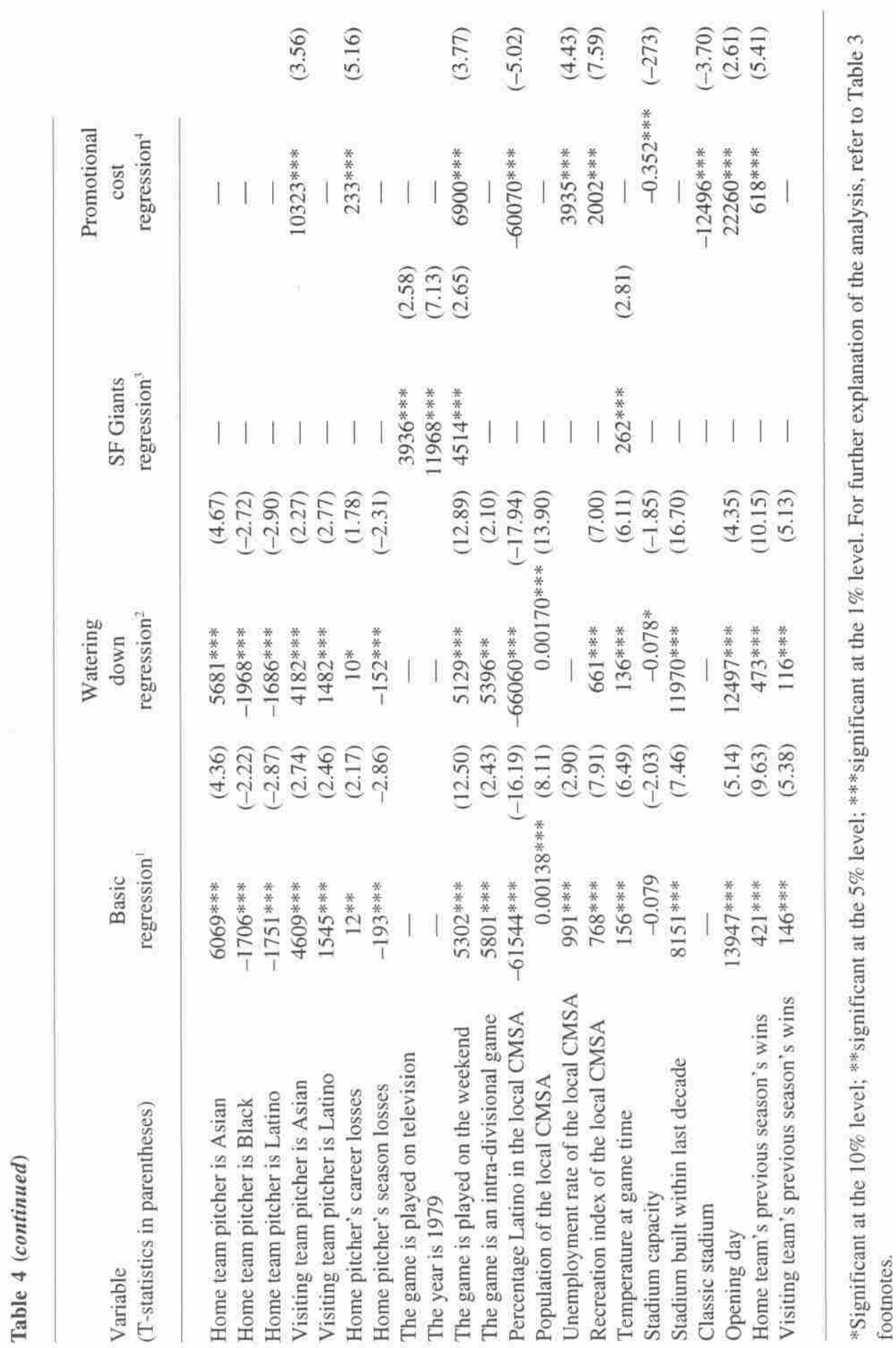


overestimate because of "cherry picking," when a customer chooses to substitute a promotional game for a non-promotional game. This doesn't add anything to seasonal attendance; it just changes the timing of the attendance.

Additionally, this line of research can potentially assist sport franchises in the development of a comprehensive promotional strategy. To this end, future research endeavors will need to address a number of issues, such as (a) what the optimal spacing is between promotion days, (b) which items are best received and in what order (magnetic schedule obviously at the beginning of the season), (c) which items have the best return on their investment, (d) how promotional decisions should relate to the other positive attendance factors (quality of opponent, day of week, etc.), (e) how price promotions compare to nonprice promotions, and (f) what is the optimal combination of the number of promotion days and the distribution of the quality of the promotions.

\section{References}

Becker, M.A., \& Suls, J. (1983). Take me out to the ballgame: The effect of objective, social, and temporal performance information on attendance at major league baseball games. Journal of Sport Psychology, 5, 302-313.

Bird, P.J. (1982). The demand for league football. Applied Economics, 14, 637-649.

Branvold, S.E. \& Bowers, R. (1992). The use of promotions in college baseball. Sport Marketing Quarterly, 1(1), 19-24.

Burton, R. \& Cornilles, R.Y. (1998). Emerging theory in team sport sales: Selling tickets in a more competitive arena. Sport Marketing Quarterly, 7(1), 29-37.

Cornwell, T.B. (1995). Sponsorship-linked marketing development. Sport Marketing Quarterly, 4(4), 13-24.

Drever, P., \& MacDonald, J. (1981). Attendances at South Australian football games. International Review of Sport Sociology, 16(2), 103.

Fizel, J.L., \& Bennett, R.W. (1989). The impact of college football telecasts on college football attendance. Social Science Quarterly, 7, 980-988.

Helson, H. (1964). Adaptation-level theory. New York: Harper \& Row.

Hill, J.R., Madura, J., \& Zuber, R.A. (1982). The short run demand for major league baseball. Atlantic Economic Journal, 10(2), 31-35.

Hoang, H. \& Racher, D.A. (1999). The NBA, exit discrimination, and career earnings. Industrial Relations, January, 1999.

Jones, J.C.H. (1984). Winners, losers, and hosers: Demand and survival in the National Hockey League. Atlantic Economic Journal, 10(3), 54-63.

Kalwani, M.U., Yim, C., Rinne, H.J., \& Sugita, Y. (1990). A price expectation model of customer brand choice. Journal of Marketing Research, 27, 251-262.

Kamen, J. \& Toman, R. (1970). Psychophysics of prices. Journal of Marketing Research, 8, 252-257.

Kotler, P. (1994). Marketing management: Analysis, planning, implementation, and control. Englewood Cliffs, NJ: Prentice Hall.

Kumar, V. \& Pereira, A. (1995). Explaining the variation in short-term sales response to retail price promotions. Journal of the Academy of Marketing Science, 23(3), 155169.

Mullin, B.J., Hardy, S., \& Sutton, W.A. (1993). Sport Marketing. Champaign, IL: Human Kinetics. 
Nagle, T.T. (1987). The strategy and tactics of pricing. Englewood Cliffs, NJ: PrenticeHall.

Noll, R.G. (1974). Government and the sports business. Washington, D.C. The Brookings Institute.

Rascher, Daniel A. (1999). The optimal distribution of talent in major league baseball. In L. Hadley, E. Gustafson, \& J. Fizel. (Eds.) Sports Economics: Current Research. Westport, CT: Praeger Press.

Schurr, K.T., Wittig, A.F., Ruble, V.E., \& Ellen, A.S. (1987). Demographic and personality characteristics associated with persistent, occasional, and non-attendance of university male basketball games by college students. Journal of Sport Behavior, 11(1), 317.

Schwartz, J.M. (1973). Causes and effects of spectator sports. International Review of Sport Sociology, 34(8), 25-45.

Scully, G.W. (1974). Pay and performance in major league baseball. American Economic Review, 64, 915-930.

Siegfried, J.J. \& Eisenberg, J.D. (1980). The demand for minor league baseball. Atlantic Economic Journal, 8, 59-66.

Take 'em out to the ballpark. (1998, April 22). USA Today, p. 12c.

Wall, G.V. \& Myers, K. (1989). Factors influencing attendance: Toronto Blue Jays game. Sport Place International: An International Magazine of Sports Geography, 3(1), 29-33.

Winer, R.S. (1986). A reference price model of brand choice for frequently purchased products. Journal of Consumer Research, 13, 250-256.

Zhang, J.J., Pease, D.G., Hui, S.C. \& Michaud, T.J. (1995). Variables affecting the spectator decision to attend NBA games. Sport Marketing Quarterly, 4(4), 29-39.

Zhang, J.J. \& Smith, D.W. (1997). Impact of broadcasting on the attendance of professional basketball games. Sport Marketing Quarterly, 6(1), 23-29.

\section{Notes}

'These variables were chosen based on a review of the literature, on the availability of data, and on knowledge regarding the theory of demand. Ultimately, the data will determine their applicability.

${ }^{2} \mathrm{~A}$ fixed effects model could capture these effects on an aggregate level, but their independent effect would remain unknown.

${ }^{3}$ The promotional dates variable was collected from each team separately via their pocket schedules. Fantastic Sports Merchandise Inc. kindly gave us the promotional item costs. All of the rest of the variables came from Rascher (1999), where they were gathered from box scores in the newspaper (time varying variables) or from various other sources (time independent variables).

${ }^{4}$ Table 3 contains the full models for each type of analysis. Table 4 contains the results of a stepwise analysis for each of the models. The parsimonious models, as expected, have higher F-statistics. Thus, they are efficient versions of the full model results containing only the significant variables.

${ }^{5}$ More complete interpretations of the control variables can be found in Rascher (1999). For brevity's sake, a sampling of the results from the basic regression (the first numerical column of Table 3) will be explained here. For every $\$ 10$ increase in the Fan Cost Index, over 1,000 fewer fans will attend per game. American League games draw over 2,000 fewer 
fans than National League games, ceteris paribus. Black pitchers are discriminated against, lowering per game attendance by about $5 \%$. There appears to be a $15-20 \%$ attendance premium for Asian pitchers. Weekend games and intradivisional (rivalry) games raise attendance, on the margin, by about $20-25 \%$. About 1,500 additional fans attend each game per one million increase in the local population. This is a remarkably consistent statistic over time and across cities (see Rascher, 1999). As previously found, baseball appears to be an inferior good exhibiting a larger number of customers during areas of higher unemployment. New stadiums draw about 10,000 more fans per game. Opening day draws over 10,000 patrons compared to a typical day at the park. A team with ten more wins for the previous season will increase attendance by about 4,300 more fans per game. Even visiting teams that fared well the year before attract more fans.

${ }^{6}$ Each variable contained a one if the game was a promotional date for a particular team and a zero if the date was not a promotional date for that team. A separate variable was created for each team.

${ }^{7}$ Higher measures of impact would be associated with fewer games, according to the hypothesis that a watering down effect exists.

${ }^{8}$ In terms of profitability, we are unable to measure the optimal strategy without knowledge of both the overhead costs of a promotional department and the fixed costs of each promotional day.

The control variables were television (dummy variable for whether the game was televised), night game, temperature, weekend, and year (1 for 1979 and 0 for 1996). 